\title{
Training in neurology: Flexibility and adaptability of a neurology training program at the epicenter of COVID-19
}

Shashank Agarwal, MD, * Sakinah Sabadia, MD,* Nada Abou-Fayssal, MD, Arielle Kurzweil, MD, Laura J. Balcer, MD, MSCE, and Steven L. Galetta, MD

Neurology ${ }^{\circledR}$ 2020;94:e2608-e2614. doi:10.1212/WNL.0000000000009675

\begin{abstract}
Objective

To outline changes made to a neurology residency program in response to coronavirus disease 2019 (COVID-19).
\end{abstract}

\section{Methods}

In early March 2020, the first cases of COVID-19 were announced in the United States. New York City quickly became the epicenter of a global pandemic, and our training program needed to rapidly adapt to the increasing number of inpatient cases while being mindful of protecting providers and continuing education. Many of these changes unfolded over days, including removing residents from outpatient services, minimizing the number of residents on inpatient services, deploying residents to medicine services and medical intensive care units, converting continuity clinic patient visits to virtual options, transforming didactics to online platforms only, and maintaining connectedness in an era of social distancing. We have been able to accomplish this through daily virtual meetings among leadership, faculty, and residents.

\section{Results}

Over time, our program has successfully rolled out initiatives to service the growing number of COVID-related inpatients while maintaining neurologic care for those in need and continuing our neurologic education curriculum.

\section{Conclusion}

It has been necessary and feasible for our residency training program to undergo rapid structural changes to adapt to a medical crisis. The key ingredients in doing this successfully have been flexibility and teamwork. We suspect that many of the implemented changes will persist long after the COVID-19 crisis has passed and will change the approach to neurologic and medical training.

\author{
Correspondence \\ Dr. Kurzweil \\ arielle.kurzweil@ \\ nyulangone.org
}

\section{MORE ONLINE}

COVID-19 Resources

For the latest articles, invited commentaries, and blogs from physicians around the world NPub.org/COVID19 


\section{Glossary}

APP $=$ advanced practice providers; $\mathbf{C D C}=$ Centers for Disease Control and Prevention; COVID-19 = coronavirus disease 2019; CSE = clinical skills evaluations; FGP = faculty group practice; ICU = intensive care unit; NYU = New York University;

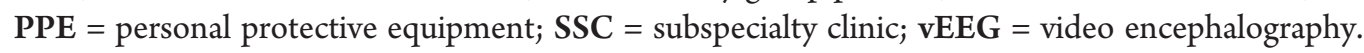

The first cases of novel coronavirus disease 2019 (COVID-19) were reported in December 2019, originating in Wuhan, China. ${ }^{1}$ The disease spread rapidly worldwide, becoming a public health emergency of international concern, and the World Health Organization declared COVID-19 a pandemic on March 11, $2020{ }^{2}$ As of April 1, 2020, there were 926,095 cases worldwide. The United States reported the highest number of cases, with 209,071 affected patients and 4,633 deaths, with New York City accounting for 83,948 cases and 1,941 deaths. $^{3}$

Physicians have always been at the forefront of deadly outbreaks worldwide and, as a result, have potentially been infected by the same diseases as their patients. Residents provide the bulk of direct patient contact within teaching hospitals and are therefore at risk of exposure to communicable disease. This pandemic has drastically changed the lives and the outlook of residents in an incredibly short period of time.

In this article, we describe modifications made to various aspects of neurology residency training program at New York University (NYU) Grossman School of Medicine's teaching hospitals during the COVID-19 pandemic. Our training sites include NYU Langone Health Manhattan, Bellevue Hospital, Manhattan Veterans' Affairs Medical Center, and NYU Langone Health-Brooklyn. Changes have been made to minimize work disruptions while respecting public health guidance. Our goals have been to continue resident education, promote safe patient care, and best manage the use of available resources, including personnel and personal protective equipment (PPE). A summary of these changes can be found in table 1 .

\section{Inpatient and consult services}

The inpatient and consult teams have been scaled down and limited to schedules of 1 attending neurologist and 1 resident for each service. The remainder of individuals on the team (residents and advanced practice providers [APPs]) have been placed on "jeopardy" call or deployed to intensive care units (ICUs), medical units, or the emergency department. When caring for patients with COVID-19, only 1 member of the neurology inpatient team (usually the attending physician) will see the patient directly to minimize exposure and to preserve PPE. Residents directly evaluate patients with COVID-19 when the attending physicians are not present such as during overnight calls or when patients are unstable. All residents are available to provide assistance. Residents on work exemptions due to chronic immunosuppression or pregnancy have been enlisted to help remotely and to supervise daily signoff, help with prerounds, participate remotely in daily rounds, help with entering orders, and take charge of the daily calls to family members. Procedures such as lumbar punctures on patients with confirmed or suspected COVID-19 are performed by attending physicians (when available) to avoid exposure to multiple personnel. Residents are expected to perform these procedures when on overnight calls or during the day if a procedure is needed urgently and the attending physician is unavailable. Neurology consult requests for patients with COVID19 are reviewed by the neurology attending physicians to ensure medical necessity for such consults. One person from each team obtains a focused history and examination; follow-up visits with direct contact are performed when needed. A method of interacting with patients virtually in the hospital called Jabber is newly available. A provider downloads the Jabber app on his or her mobile device and is able to use this to securely dial into a patient's room through MyWall, an interface on every patient's hospital room TV. Anecdotally, this has been difficult to use for many of the inpatient neurology consults for which an examination is crucial or the reason for consultation is altered mental status. Nonetheless, this is a new technology being introduced now, and it may have more utility for different types of consults. The technology allows an attending or resident to be remotely involved with an inpatient consult and could enhance supervision for the trainee. Furthermore, a qualified assistant such as a nurse could be available to aid with the encounter.

\section{Epilepsy monitoring unit}

In accordance with the City of New York Office of the Mayor Emergency Executive Order, all elective procedures and hospital admissions have been canceled in light of the coronavirus pandemic. ${ }^{4}$ These have included elective admissions to the epilepsy monitoring service for video encephalography (vEEG). Epilepsy monitoring unit census across all affiliated hospitals currently comprises patients admitted directly from the emergency department. Coverage of these patients is currently maintained by a shared general neurology resident or an APP. Designated epilepsy monitoring unit residents have been deployed to cover medical or neurology services.

\section{Stroke emergencies (stroke codes) and consults}

The stroke team who usually responds to stroke codes includes a resident, an APP, and, occasionally, a fellow. The response team is now reduced to 1 resident; the remainder of the team has been deployed elsewhere in ICUs, medical inpatient units, and the emergency department. All patients presenting as 
Table 1 Summary of adaptations made to NYU neurology residency during COVID-19

\begin{tabular}{ll}
\hline Aspect of the residency program & Adaptation \\
\hline Inpatient neurology services & $\begin{array}{l}\text { Skeleton services minimizing team numbers, 1 team member physically rounding on patients with COVID; } \\
\text { use of Jabber app to interact remotely with inpatients via their MyWall on the hospital room television }\end{array}$ \\
\hline Epilepsy monitoring units & All elective admissions canceled; urgent admissions through the ED only \\
\hline Stroke codes & 1 Resident responds wearing an N95 mask, a face shield, a gown, and gloves \\
\hline Neuro-ICU & 1 Resident plus 1 attending team, use of Ceribell (bedside EEG band) to monitor for nonconvulsive seizures \\
\hline Resident continuity clinics & All in-person appointments have been rescheduled to telephone or video visits \\
\hline $\begin{array}{l}\text { Ambulatory rotations (subspecialty clinic, } \\
\text { urgent care, elective) }\end{array}$ & $\begin{array}{l}\text { These rotations are on hold for now; instead, residents are providing services for COVID telephone } \\
\text { hotlines, working on scholarly activity, acting as jeopardy for sick residents, or working in the COVID } \\
\text { medicine units and ICUs }\end{array}$ \\
\hline Didactics & $\begin{array}{l}\text { Didactics including grand rounds, morning report, professors' rounds, research curriculum, journal club, } \\
\text { and others have been converted to an online-only platform }\end{array}$ \\
\hline Support & $\begin{array}{l}\text { Bimonthly resident forums are now occurring twice weekly with an online platform; a nightly update e- } \\
\text { mail is sent; virtual support groups are held weekly; virtual happy hours are held weekly; food is supplied } \\
\text { to those in the hospitals }\end{array}$ \\
\hline
\end{tabular}

Abbreviations: COVID-19 = coronavirus disease 2019; ED = emergency department; ICU = intensive care unit; NYU = New York University.

stroke codes in the emergency departments across NYUaffiliated sites are currently being screened for COVID-19. PPE for high-risk patients is in accordance with Centers for Disease Control and Prevention (CDC) guidelines and includes an N95 mask covered with a surgical mask, a face shield, a gown, and gloves. ${ }^{5}$ The NIH Stroke Scale is being performed after initial CT of the brain to preserve PPE. For stroke codes in the COVID-19 unit, the resident verifies with the team and any collateral source the timing of neurologic deficits and reviews the chart for medical history and hospital course before discussing with the stroke attending physician; it is then determined whether a neurologic examination is warranted. From these discussions, if a determination is made for an emergent neurologic examination, then the resident uses appropriate PPE while examining the patient before imaging is obtained.

\section{Neuro-ICU}

Two of the 4 NYU Langone Health hospital sites currently have neuro-ICUs where critically ill patients with primary neurologic diagnoses are cared for by neuro-intensivists. The teams on these units include a resident, an APP, and a neuroICU attending physician. The neuro-ICU team is now made up of solely a resident and attending, and the daily rounding protocol is similar to those of the inpatient stroke and general neurology teams. Because many of the neuro-ICU patients require vEEG monitoring, patients with confirmed or suspected COVID-19 are monitored with Ceribell-Rapid Response EEG. ${ }^{6}$ Ceribell is a 10-electode headband that is quick and easy to place; it can be used to assess for nonconvulsive status epilepticus. This placement is currently done by the EEG technicians (during the daytime) or the resident (during night shifts). The use of Ceribell instead of vEEG units limits exposure of the EEG technicians who would otherwise need to be in close contact with the patient for extended periods of time.

\section{Resident continuity clinics}

Throughout the 3 years of neurology residency training, residents follow up patients in their continuity clinics under the supervision of attending faculty. Patients seen in these clinics include those recently discharged from the hospital and referrals from the emergency department, primary care, or other subspecialty clinics (SSCs). Residents' clinics have transitioned to a telemedicine model to limit close contact between patients and providers and to promote physical distancing while facilitating access to neurologic care during the COVID-19 pandemic. Patients are called before their visits by support staff and consented to switch their visit to a virtual health visit; these have included video visits (for those patients with video capabilities on a smartphone or iPad) or phone visits for those without video capabilities. At the time of the call, the support staff review the logistics of the upcoming virtual visit with the patient. Some patients have opted to reschedule their routine visits given a preference for in-person communication. Virtual visits are conducted by residents and other providers from home using remote access to the medical record. For telephone visits, a resident makes the call and provides an assessment and plan. If residents have a second phone line, they place the patient on hold and call the supervising attending physician at an offsite location to review the case before finalizing with the patient. If there is no second phone line, the resident hangs up with the patient, phones the attending physician to review the case, then calls the patient back with final recommendations. Documentation is placed remotely in the chart by the residents, and then an attestation is made by the supervising attending. In the case of video visits, 2 providers can sign in simultaneously to 
a patient's video visit via Haiku or Canto on EPIC. This allows direct attending supervision. Alternatively, Haiku to Haiku is a new feature that allows clinician-to-clinician video communication; this will allow a resident to call in an attending for consultation if needed and can be done in a mobile fashion.

The ability for 2 providers to join the same virtual visit will enable virtual clinical skills evaluations (CSEs) to occur, which are now being accepted by the American Board of Psychiatry and Neurology as part of credentialing requirements to sit for an American Board of Psychiatry and Neurology Initial Certification examination. We are preparing for CSEs to begin in the upcoming weeks. A tip sheet created for residents and faculty to navigate virtual CSEs can be found in table 2. The video visit examination has been reviewed extensively by a committee of attendings; major limitations at this time include deep tendon reflexes and the fundoscopic examination.

\section{Ambulatory rotations}

During these rotation blocks, residents typically rotate through either an ambulatory urgent care rotation or an SSC rotation with faculty group practice (FGP) physicians in specialties including neuro-oncology, neuro-ophthalmology, vascular neurology, epilepsy, neuroimmunology/multiple sclerosis, epilepsy, neuromuscular medicine, headache/Botox clinic, neuro-rehabilitation, sleep medicine, movement disorders, neuro-otology, dysautonomia clinic, and behavioral neurology. These rotations have been placed on hold during the current pandemic; visits are being conducted via telehealth services among our FGP physicians. Residents on the ambulatory care rotations are on jeopardy while working at home on scholarly activities, providing services for NYU COVID-19 telephone hotlines, or volunteering on COVID-19 inpatient medical units.

\section{Virtual learning}

We have quickly learned what can be accomplished remotely and what learning topics require in-person attendance. Our residency program was already using online platforms for morning and afternoon didactic sessions to enable resident participation from various NYU hospital sites. With the travel restrictions affecting guest speakers from around the country and in an effort to keep physical distancing, weekly grand rounds lectures are now solely conducted via Webex. All other educational activities such as the Patient-Oriented Research Curriculum, journal club, biweekly continuum presentations, and case-based morning reports and professors' rounds, which previously were available via our videoconferencing bridge between hospitals, have now been converted to an online-only platform. The grand rounds lectures are recorded for future viewing. Virtual learning has made lectures and

Table 2 Virtual CSEs tip sheet

\section{No. Tip}

1 On EPIC, check individual provider schedules to see who is doing video visits in FGP practices. The following CSEs can be completed virtually outpatient: ambulatory, neurodegenerative, neuromuscular, and child neurology.

2 Contact an attending doing virtual visits to set up a virtual CSE on any of the above topics. This should be done a few days to a week in advance. Ensure that you send the attending the blank CSE evaluation form. You will provided with a list of participating attendings for each CSE.

3 For the critical illness CSE, we will try to do this inpatient if possible. Please contact one of our neuro-ICU or neurovascular faculty to arrange for a CSE to be completed on a patient without COVID.

4 For outpatient virtual CSE on the day of the encounter: monitor the EPIC screen with the attending's patient schedule. Refresh intermittently to identify when the patient signs into the visit; the video icon will turn green when the patient is in the virtual waiting room.

$5 \quad$ Resident and attending both enter the video visit through Haiku or Canto.

6 Attending: introduce yourself and your role to patient and explain that a resident will be taking the history and performing the virtual examination with you observing.

7 Resident: introduce yourself and your role and proceed with H\&P.

$8 \quad$ Once the resident completes the H\&P, attending can notify the patient that the resident will now present impression and propose a plan, and attending will fill in the finalized plan for the patient.

$9 \quad$ When finished, all parties end the call.

10 Attending is responsible for placing orders and documenting the visit.

11 Once complete and ready, attending should call the resident to provide verbal feedback about the encounter.

12 Attending should then complete the CSE evaluation form and e-mail to the resident or directly to the program coordinator.

13 The resident is responsible for getting all completed CSE forms to the program coordinator.

Abbreviations: COVID-19 = coronavirus disease 2019; CSE = clinical skills evaluations; H\&P = history and physical; ICU = intensive care unit; FGP = faculty group practice. 
didactic activities more readily available, leading to increases in attendance among residents, fellows, and faculty.

\section{Scholarly activities}

In accordance with $\mathrm{CDC}$ recommendations, the American Academy of Neurology canceled its 2020 Annual Meeting for the first time in its 72 -year history. ${ }^{7}$ Although a prudent decision, this was of course a disappointment for residents. Many had worked hard on abstracts and presentations and were looking forward to traveling to Toronto to present their research to neurologists from around the world. To offset the cancellation of various national meetings, the Annual NYU Neurology Research Symposium, usually held in May, will be postponed until the fall of 2020. This platform allows medical students, residents, and fellows to present their scholarly work. Residents who were previously scheduled for ambulatory rotations and electives and are now in a jeopardy pool are encouraged to engage in scholarly work related to our evolving understanding of and adaptations to and the potential neurologic complications of COVID-19.

\section{Global neurology elective}

NYU has a robust Global Health in Neurology program in collaboration with hospitals in Uganda and Tanzania. Each year, once in the fall and once in the spring, 2 NYU neurology residents travel with a mentor to learn neurology in resourcelimited settings. Residents who had previously secured this rotation have needed to reschedule or cancel their plans due to travel restrictions. While such a rotation requires extensive planning, paperwork, and funding, affected residents have risen to the occasion of the cancelation graciously by providing additional assistance on inpatient units and with the writing of manuscripts related to the COVID-19 response/experience.

\section{Fellowship and faculty position interviews}

As CDC travel restrictions have tightened, programs have canceled in-person fellowship interviews and have been conducting them using virtual web-based platforms. The academic medicine community is not alone in facing this challenge. LinkedIn, Google, Facebook, and Amazon have all halted on-site job interviews indefinitely and are using alternative resources for conducting virtual meetings. Various subspecialty fellowship interviews at NYU have been conducted via Webex. The interview sessions have included Webex-based didactic presentations by the fellowship program directors, followed by applicant interviews with faculty. Many of our current residents have been affected by the travel ban policy and have interviewed for fellowships on virtual platforms at institutions around the country. While virtual interviews are not ideal for applicants (they are unable to tour the academic or hospital facilities, for example), they do allow interactions with faculty, staff, and current fellows.

\section{Virtual neurology match}

On March 20, 2020, medical students around the country learned of their residency program match results. This year's match was held virtually, and the NYU neurology residency program was excited to welcome a new incoming class of residents. Each matched student was contacted by program leadership on the phone to congratulate and welcome him or her; students also enjoyed virtual celebrations with their families and friends.

\section{Resident wellness}

The COVID-19 pandemic has created physical and emotional strain on trainees. Important elements of this have included uncertainty in caring for patients with a new medical disease, fear of infection and transmission to others, and the need to work in unfamiliar areas of the hospitals; all of this has occurred while needing to keep physical distance. Virtual platforms have been helpful in maintaining connections, engaging in regular check-ins, and continuing scholarly and didactic learning. Resident forum, which was previously held twice monthly to provide an opportunity for program leadership to meet with residents informally and to discuss any residency-related topics, has now become a twice-weekly occurrence and is held virtually. We have found that given the constant flux and flow of new information surrounding this pandemic, and certainly the e-mail fatigue that comes with it, these frequent and regular virtual meetings have been essential in conveying necessary and up-to-date information. Our chairman sends a nightly e-mail with pertinent institutional updates but also infuses each e-mail with some much needed inspiration in the form of a cartoon, song, quotation, or poem. We have arranged for virtual support groups led by psychiatry and neurology-psychiatry double-boarded colleagues. A common motto in our program has been "food is love," and we have been maintaining nourishment when possible in the form of individually wrapped items. Virtual happy hours via online platforms have been enjoyable and will continue throughout this time when we all need to stay connected with our colleagues.

\section{Departmental operations}

Adjustments to departmental operations have been intertwined with changes made in our training programs. The FGPs have converted in-person visits to virtual health visits. Whereas residents once rotated in ambulatory settings such as urgent care, SSCs, and electives, some are now being asked to work on scholarly activities at home to stay healthy while waiting to relieve neurology colleagues who may become on inpatient services or assist in the medical units with patients with COVID19. Two faculty members are assigned per day to be available to see urgent virtual health visits in our offices in addition to routine subspecialty and general neurology virtual visits. At 
present, we are doing $\approx 200$ neurology virtual (video) visits a day. While attending physicians once led large teams of learners (medical students, residents, fellows, APPs) on inpatient services, we are operating on a scaled-down model in which teams are made up of 1 resident and 1 attending physician. For weekend coverage, 1 attending physician typically covers all calls for both the hospital and our neurology FGP patients. Currently, each member of the faculty covers his/her own practice on the weekends and nights in an effort to relieve the inpatient attending physician from answering phone calls while donning and doffing PPE to see patients with COVID-19.

In addition to serving the role of primary neurology resident, many neurology residents have already been deployed to medicine units, medicine ICUs, and emergency departments during their elective time given the surge of patients with COVID-19. At this time, $\approx 90 \%$ of our hospital populations comprise patients with COVID-19. To maintain safety and prevent infection transmission, all residents were required to complete online training video modules of correct practices of donning and doffing PPE. Additional in-person training has been conducted for services thought to have the highest risk of exposure to COVID-19. To optimally prepare the neurology residents, 2 sessions were scheduled with a nurse from the Infection Prevention and Control Department and streamed virtually to allow residents and faculty to tune in from offsite and to ask questions.

\section{Conclusion}

The COVID-19 pandemic has led to a sudden disruption of life as we know it. Residency training programs are no exception and have needed to remain flexible to adapt to this rapidly changing and ever-evolving situation. The structure of our various rotations, staffing, ambulatory care, and even the type of care we are providing has drastically changed. Policies put in place one day may change by the next. The role of residents during this time has been considered and has also undergone adjustments. As the numbers of COVID-19 cases have grown drastically throughout our hospitals to the hundreds, neurology residents have had increasing roles in the inpatient and emergency settings, including our medical ICUs. There is a physical need for residents to deploy to COVID-19 units; this not only has provided additional patient care and staff camaraderie but also has led to opportunities for learning and leadership. The Accreditation Council for Graduate Medical Education mandates achievements in core competencies that extend well beyond neurologic knowledge and patient care. Professionalism and systemsbased learning are particularly valuable during this pandemic, and there is much skill to be built in these domains by performing on the front lines. It has become obvious that it is necessary for residents to be deeply involved in the pandemic response on multiple levels. Our residents have shown tremendous resilience during this time and have risen to the occasion. Their eagerness to aid has been inspirational, and humanism has prevailed. And our success thus far has relied on a flexible and adaptive mindset for all aspects of a residency training program.

An important question remains unanswered: when the COVID19 crisis has passed, what changes to our training program will persist? Certainly, we hope to revert back to a better balance of inpatient and outpatient rotations for trainees. And nothing can replace the satisfaction of discussing cases together around a table or at the bedside. However, teleneurology is here to stay. Before COVID-19, we had formed a committee of faculty members and residents interested in promoting teleneurology in our clinics and educational structure and hoped this would materialize over the course of a year. Instead, circumstances forced it into existence in a matter of weeks. We speculate that we will continue to use teleneurology not only for patient care but also for education. Virtual options provide the ability for an attending to supervise resident activity remotely in both hospital and ambulatory settings. Virtual platforms have been instrumental in providing didactics and educational opportunities and the ability to record lectures and will likely persist to some extent even when in-person conferencing is allowed again. We believe that on the other end of this crisis we will be stronger as physicians and as a training program.

\section{Study funding}

No targeted funding reported.

\section{Disclosure}

S. Agarwal is a member of the editorial team for the Neurology Resident \& Fellow Section. S. Sabadia, N. Abou-Fayssal, A. Kurzweil, L. Balcer, and S. Galetta report no relevant disclosures. Go to Neurology.org/N for full disclosures.

\begin{tabular}{|c|c|c|}
\hline Name & Location & Contribution \\
\hline $\begin{array}{l}\text { Shashank Agarwal, } \\
\text { MD }\end{array}$ & $\begin{array}{l}\text { NYU Langone Health, } \\
\text { New York }\end{array}$ & $\begin{array}{l}\text { Writing/editing the } \\
\text { manuscript }\end{array}$ \\
\hline $\begin{array}{l}\text { Sakinah Sabadia, } \\
\text { MD }\end{array}$ & $\begin{array}{l}\text { NYU Langone Health, } \\
\text { New York }\end{array}$ & $\begin{array}{l}\text { Writing/editing the } \\
\text { manuscript }\end{array}$ \\
\hline $\begin{array}{l}\text { Nada Abou- } \\
\text { Fayssal, MD }\end{array}$ & $\begin{array}{l}\text { NYU Langone Health, } \\
\text { New York }\end{array}$ & $\begin{array}{l}\text { Writing/editing the } \\
\text { manuscript }\end{array}$ \\
\hline $\begin{array}{l}\text { Arielle Kurzweil, } \\
\text { MD }\end{array}$ & $\begin{array}{l}\text { NYU Langone Health, } \\
\text { New York }\end{array}$ & $\begin{array}{l}\text { Writing/editing the } \\
\text { manuscript }\end{array}$ \\
\hline $\begin{array}{l}\text { Laura J. Balcer, MD, } \\
\text { MSCE }\end{array}$ & $\begin{array}{l}\text { NYU Langone Health, } \\
\text { New York }\end{array}$ & $\begin{array}{l}\text { Writing/editing the } \\
\text { manuscript }\end{array}$ \\
\hline $\begin{array}{l}\text { Steven L. Galetta, } \\
\text { MD }\end{array}$ & $\begin{array}{l}\text { NYU Langone Health, } \\
\text { New York }\end{array}$ & $\begin{array}{l}\text { Writing/editing the } \\
\text { manuscript }\end{array}$ \\
\hline
\end{tabular}

\section{References}

1. World Health Organization. Pneumonia of unknown cause-China. 2020. Available at: who.int/csr/don/05-january-2020-pneumonia-of-unkown-cause-china/en/. Accessed April 1, 2020

2. World Health Organization Declares COVID-19 a Pandemic. 2020. Available at: who. $\mathrm{int} / \mathrm{dg} /$ speeches/detail/who-director-general-s-opening-remarks-at-the-media-briefing-on-covid-19-11-march-2020. Accessed April 1, 2020. 
3. Johns Hopkins Coronavirus Resource Center; 2020. Available at: coronavirus.jhu. edu/map.html. Accessed April 1, 2020.

4. City of New York Office of the Mayor Emergency Executive Order No.100. 2020. Available at: wwwl.nyc.gov/assets/home/downloads/pdf/executive-orders/2020/ eeo-100.pdf. Accessed April 1, 2020.

5. Interim infection prevention and control recommendations for patients with suspected or confirmed coronavirus disease 2019 (COVID-19) in healthcare settings
2020. Available at: cdc.gov/coronavirus/2019-ncov/infection-control/control-recommendations.html?CDC_AA_refVal=https $\% 3 \mathrm{~A} \% 2 \mathrm{~F} \% 2 \mathrm{Fwww} . c d c . g o v \% 2 \mathrm{Fcor}-$ onavirus\%2F2019-ncov\%2Fhcp\%2Finfection-control.html. Accessed April 1, 2020.

6. Ceribell-rapid response EEG. 2020. Available at: ceribell.com/index.html. Accessed April 1, 2020.

7. AAN Annual Meeting: COVID-19 (March 2020). Available at: aan.com/conferencescommunity/annual-meeting/general-info/covid-19/. Accessed April 1, 2020. 


\section{Neurology}

\section{Training in neurology: Flexibility and adaptability of a neurology training program at the epicenter of COVID-19}

Shashank Agarwal, Sakinah Sabadia, Nada Abou-Fayssal, et al.

Neurology 2020;94;e2608-e2614 Published Online before print May 8, 2020

DOI 10.1212/WNL.0000000000009675

This information is current as of May 8, 2020

\section{Updated Information \&} Services

Citations

Subspecialty Collections

Permissions \& Licensing

Reprints including high resolution figures, can be found at: http://n.neurology.org/content/94/24/e2608.full

This article has been cited by 2 HighWire-hosted articles: http://n.neurology.org/content/94/24/e2608.full\#\#otherarticles

This article, along with others on similar topics, appears in the following collection(s):

All Education

http://n.neurology.org/cgi/collection/all_education

Health systems

http://n.neurology.org/cgi/collection/health_systems

Information about reproducing this article in parts (figures,tables) or in its entirety can be found online at:

http://www.neurology.org/about/about_the_journal\#permissions

Information about ordering reprints can be found online:

http://n.neurology.org/subscribers/advertise

Neurology ${ }^{\circledR}$ is the official journal of the American Academy of Neurology. Published continuously since 1951, it is now a weekly with 48 issues per year. Copyright (C 2020 American Academy of Neurology. All rights reserved. Print ISSN: 0028-3878. Online ISSN: 1526-632X.

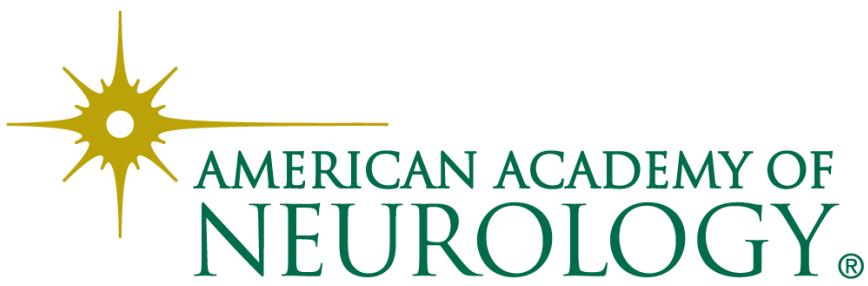

